\title{
Kawasaki disease with pulmonary nodules: two case reports and literature review
}

\author{
Dandan Song, Xiuqin Liu \\ Department of Pediatrics, Qingdao Municipal Hospital, Qingdao University, Qingdao, China \\ Correspondence to: Xiuqin Liu. Department of Pediatrics, Qingdao Municipal Hospital, Qingdao University, 5 Donghaizhong Road, Shinan, Qingdao \\ 266001, China. Email: liuxiuqin2021@163.com.
}

\begin{abstract}
In this study, we report case studies of two infants diagnosed with Kawasaki disease with pulmonary nodules. The typical symptoms of Kawasaki disease include changes to the lips and oral cavity, including reddening of the lips and strawberry tongue, the diffuse injection of oral and pharyngeal mucosa, a rash (including redness at the site of the Bacille Calmette-Guerin inoculation), and changes to peripheral extremities, which in the initial stage include the reddening of palms and soles and edema, and in the convalescent stage include periungual desquamation and non-suppurative cervical lymphadenopathy. One of the patients had mild, transient bilateral conjunctival redness, and the other patient had a fever. However, chest imaging revealed multiple lung nodules, and echocardiography revealed coronary artery dilatation. Based on the symptoms, the laboratory indicators and echocardiography, diagnoses of incomplete Kawasaki disease were confirmed. The physicians provided treatments to the patients that significantly alleviated their conditions, including intravenous immunoglobulin (IVIG) and aspirin. The coronary arteries of the two infants returned to normal, and the lung nodules of the two infants disappeared. We conducted a literature search and identified publications in which nine children reported pulmonary nodules associated with Kawasaki disease. At present, lung damage remains a challenge in diagnosing and differential diagnosis of Kawasaki disease and incomplete Kawasaki disease.
\end{abstract}

Keywords: Kawasaki disease; pulmonary nodules; coronary artery involvement; case report

Submitted Feb 18, 2021. Accepted for publication May 25, 2021.

doi: 10.21037/tp-21-66

View this article at: https://dx.doi.org/10.21037/tp-21-66

\section{Introduction}

Kawasaki disease is an acute systemic vasculitis syndrome in children, mainly involving the small and medium blood vessels, and is often accompanied by damage to the nervous system, digestive system, muscles, joints, and urinary system $(1,2)$. A diagnosis of complete Kawasaki disease can be established if the child presents with a fever for $\geq 4$ days along with four of the five other principal clinical findings. A diagnosis of incomplete (sometimes referred to as atypical) Kawasaki disease should be considered for any infant or child with prolonged unexplained fever, fewer than four of the principal clinical findings, and compatible laboratory or echocardiographic findings (3). Coronary artery abnormalities are the most severe complication, which has been reported in $25 \%$ of patients with Kawasaki disease. Echocardiography is considered positive for purposes of this algorithm if any of three conditions are met: Z-score for the left anterior descending coronary artery or the right coronary artery of $\geq 2.5$; a coronary artery aneurysm; or the existence of $\geq 3$ other suggestive features, including decreased left ventricular function, mitral regurgitation, pericardial effusion, or Z-scores in the left anterior descending coronary artery or the right coronary artery of 2 to 2.5 (4). The revised guidelines recommend the use of $Z$-scores to define coronary artery dilation. If a $\mathrm{Z}$-score for an internal coronary artery diameter is $\geq 2.5$ standard deviation (SD) units, it is defined as a coronary artery dilation. However, if an examiner faces difficulties in using a $Z$-score, the conventional criteria for traditional measurements (i.e., an inner diameter $\geq 3 \mathrm{~mm}$ for 

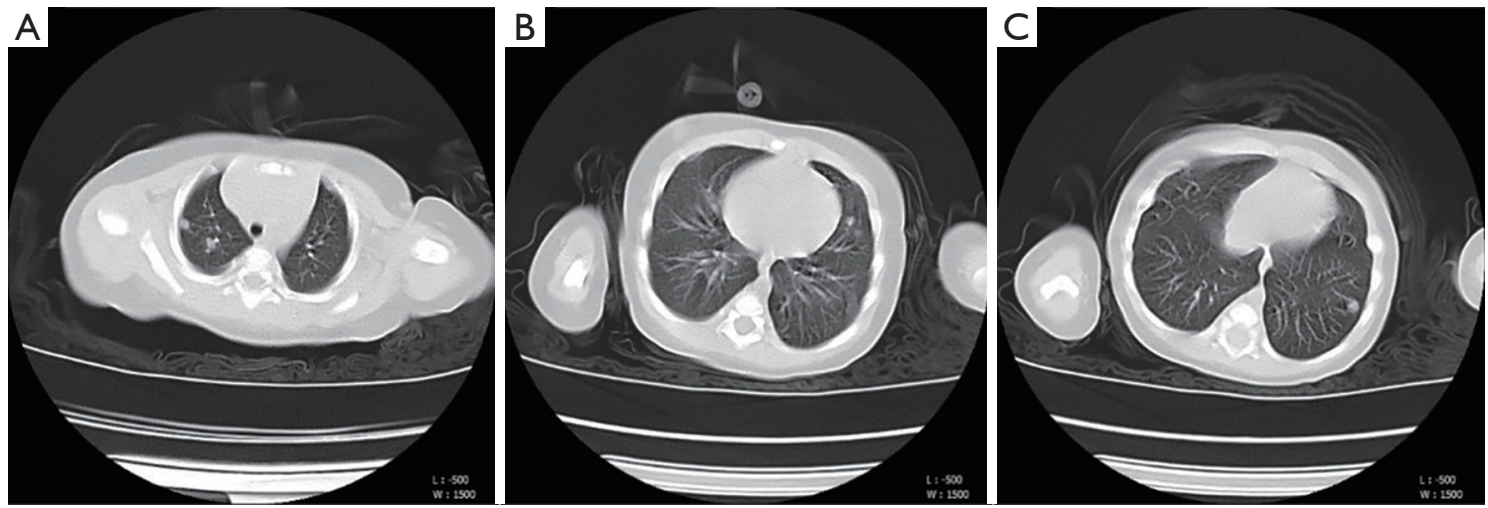

Figure 1 First imaging findings of patient 1 (A,B,C): a CT scan of the chest showed the upper lobe of the bilateral lungs and the lower lobe of the left lung was nodular and patchy. CT, computed tomography.

children $<5$ years old, or $\geq 4 \mathrm{~mm}$ for children $\geq 5$ years old) can be used for the diagnosis of coronary artery dilation (3).

Patients with severe coronary artery involvement may also develop aneurysms of other medium-sized arteries, including the axillary, subclavian, brachial, femoral, iliac, splanchnic, and mesenteric arteries (4). However, concomitant lung damage is rare and has only been observed in a small number of children with Kawasaki disease and incomplete Kawasaki disease. At present, lung damage remains a challenge in diagnosing and differential diagnosis of Kawasaki disease and incomplete Kawasaki disease (5-10).

This article retrospectively analyzed the clinical manifestations, laboratory examinations, imaging characteristics, diagnosis, treatment, and prognosis of two infants with Kawasaki disease complicated with multiple pulmonary nodules. A comprehensive review of the relevant literature was also undertaken.

We present the following case in accordance with the CARE reporting checklist (available at https://dx.doi. org/10.21037/tp-21-66).

\section{Case presentations}

Patient 1 , a previously healthy 83 -day-old boy, presented with 10 days of cough and half a day of low-grade fever. At that time, his father had an upper respiratory tract infection. Initial laboratory studies revealed white blood cells (WBCs) of $13.95 \times 10^{9} / \mathrm{L}$, a neutrophils percentage of $45.90 \%$, a hemoglobin level of $103 \mathrm{~g} / \mathrm{L}$, platelets (PLTs) of $507 \times 10^{9} / \mathrm{L}$, and C-reactive protein (CRP) of $33.98 \mathrm{mg} / \mathrm{L}$. A chest computed tomography (CT) showed that the upper lobe of the patient's bilateral lungs and the lower lobe of the left lung were nodular and patchy (see Figure 1A,B,C). The first impression was bronchopneumonia, and the initial treatment was piperacillin sodium $(100 \mathrm{mg} / \mathrm{kg} / \mathrm{d})$ and erythromycin $(15 \mathrm{mg} / \mathrm{kg} / \mathrm{d})$. The patient's temperature was normal, and the cough stopped after 3 days. However, 1 week later, the laboratory tests revealed thrombocytosis $\left(824 \times 10^{9} / \mathrm{L}\right)$, elevated WBCs $\left(20.61 \times 10^{9} / \mathrm{L}\right)$ with neutrophil predominance, and elevated acute phase reactants, such as a CRP of $66 \mathrm{mg} / \mathrm{L}$ and an erythrocyte sedimentation rate (ESR) of $44.00 \mathrm{~mm} / \mathrm{h}$. During this period, the patient also had diarrhea. The results of cultures from his urine, blood, and stool were negative. Questions arose about his lung nodules, and we tested for the respiratory syncytial virus, adenovirus, influenza virus, Streptococcus pneumoniae, chlamydia, fungi, and other pathogenies to exclude the possibility of virus, tuberculosis, fungi, tumors, and so on. Due to the special period of the epidemic, we ruled out the possibility of severe acute respiratory syndrome coronavirus-2 (SARS-CoV-2) infection. The SARS-CoV-2 viral nucleic acid detection and serum-specific antibody detection were also negative. As no clear pathogens were found, we stopped all antibiotics. Meanwhile, the patient was observed to have a mild, transient bilateral conjunctival redness. He had no skin rash, no lymphadenopathy, and his range of motion was normal for all joints. Additionally, a physical examination showed a clear chest, normal heart sounds, and a soft abdomen without hepatosplenomegaly. The results of his neurological examination were normal. A repeat chest CT revealed that the lung nodules had increased in number and were larger than before (see Figure $2 A, B, C)$. Echocardiography revealed a fusiform 

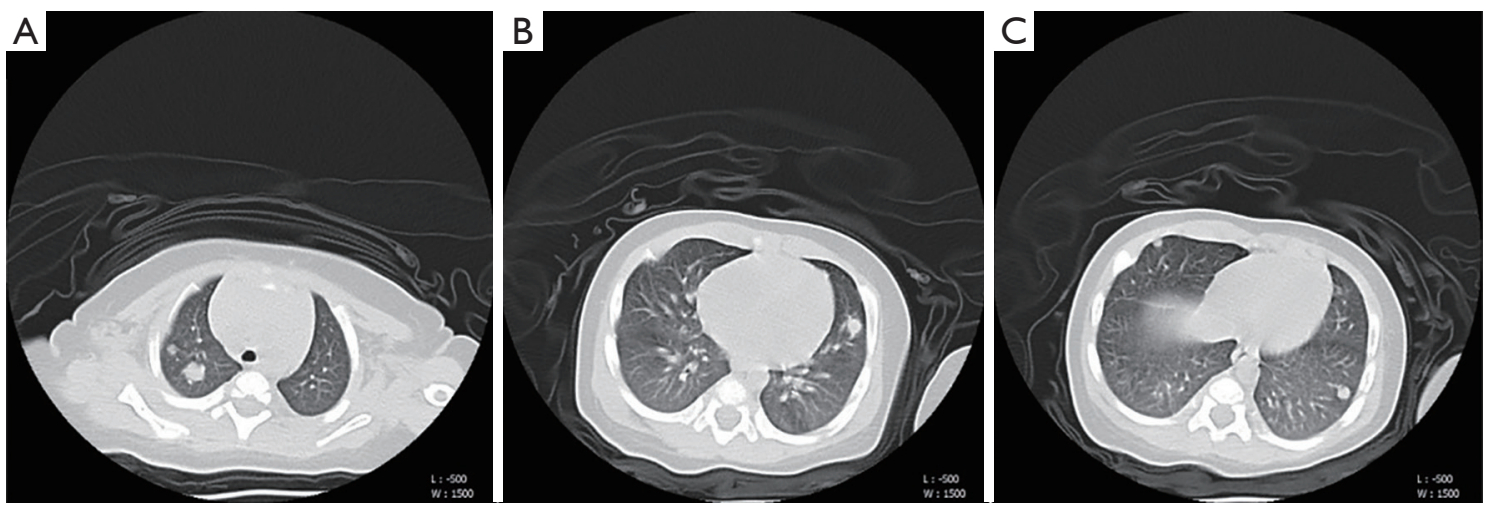

Figure 2 Second imaging findings of patient 1 (A,B,C): a CT scan of the chest 1 week later showed that the pulmonary nodules had increased in number and were larger than before. CT, computed tomography.

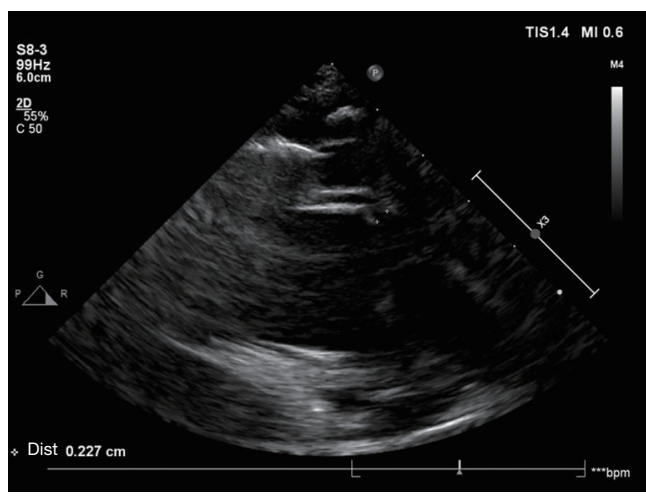

Figure 3 Right coronary artery picture of patient 1

right coronary artery (2.3 $\mathrm{mm}$ in diameter) (see Figure 3) and a mildly dilated left main coronary artery $(4.0 \mathrm{~mm}$ in diameter) (see Figure 4). The patient's diagnosis of Kawasaki disease was confirmed. He was immediately treated with intravenous immunoglobulin (IVIG) $(2 \mathrm{~g} / \mathrm{kg} / \mathrm{d})$ and aspirin $(30 \mathrm{mg} / \mathrm{kg} / \mathrm{d})$. After 1 week, the patient's WBCs, PLTs, and CRP were normal. He did not present with any periungual desquamation in the subacute phase. Echocardiography was taken of his right coronary artery (1.6 $\mathrm{mm}$ in diameter) (see Figure 5) and left main coronary artery $(2.6 \mathrm{~mm}$ in diameter) (see Figure 6) 4 weeks later. After discharge, a follow-up appointment indicated that the lung nodules had disappeared some 2 months later (see Figure $7 A, B, C$ ).

Patient 2, a 38-day-old boy, was admitted with a 2-day history of high fever and irritability. He had been physically healthy previously. He had no skin rash, no erythema, no cracking of the lips, no strawberry tongue, no erythema of oral or pharyngeal mucosa, no lymphadenopathy,

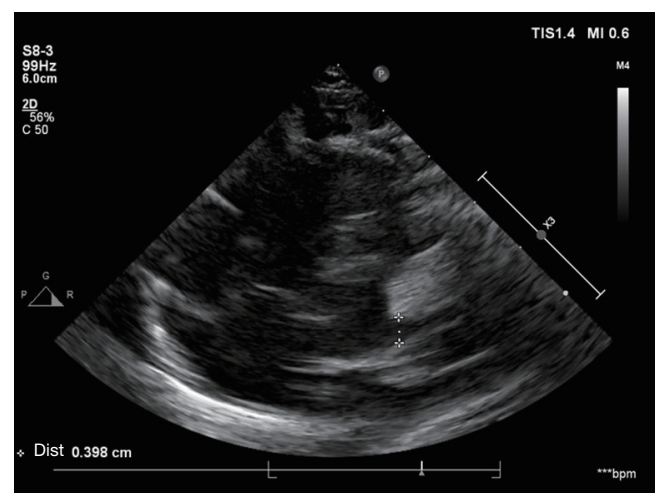

Figure 4 Left coronary artery picture of patient 1.

no erythema and edema of the hands or feet, and/or periungual desquamation, and his range of motion was normal for all joints. A physical examination showed a clear chest, normal heart sounds, and a soft abdomen without hepatosplenomegaly. The results of the neurological examination were normal. A laboratory examination showed WBCs of $10.69 \times 10^{9} / \mathrm{L}$, a neutrophils percentage of $35.30 \%$, PLTs of $181 \times 10^{9} / \mathrm{L}, \mathrm{CRP}$ of $11.49 \mathrm{mg} / \mathrm{L}$, an ESR of $33 \mathrm{~mm} / \mathrm{h}$, and an alanine aminotransferase of $224.53 \mathrm{U} / \mathrm{L}$. We also tested for a respiratory syncytial virus, adenovirus, influenza virus, Streptococcus pneumoniae, chlamydia, tuberculosis, fungi to exclude the possibility of infection. The SARS-CoV-2 viral nucleic acid detection and the serum-specific antibody detection were also negative. The patient's cerebrospinal fluid was normal. The chest radiograph indicated left lung nodules (see Figure 8). There was no clinical response after 3 days of antibiotic treatment of ceftriaxone $(80 \mathrm{mg} / \mathrm{kg} / \mathrm{d})$. The repeated laboratory data 


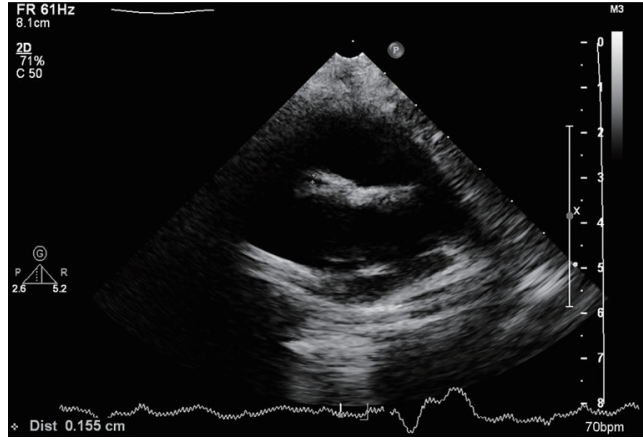

Figure 5 Reviewed right coronary artery picture of patient 1.

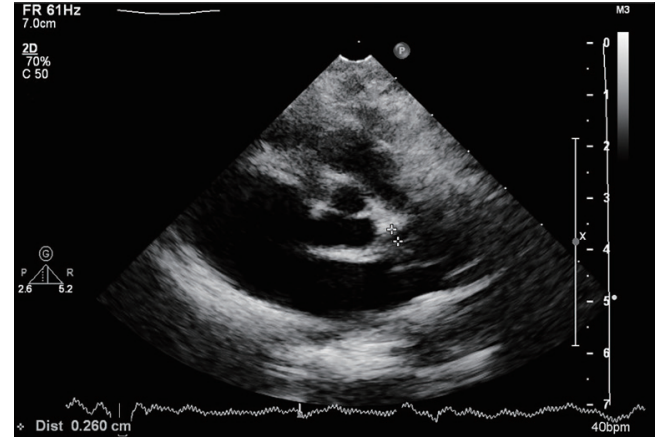

Figure 6 Reviewed left coronary artery picture of patient 1.
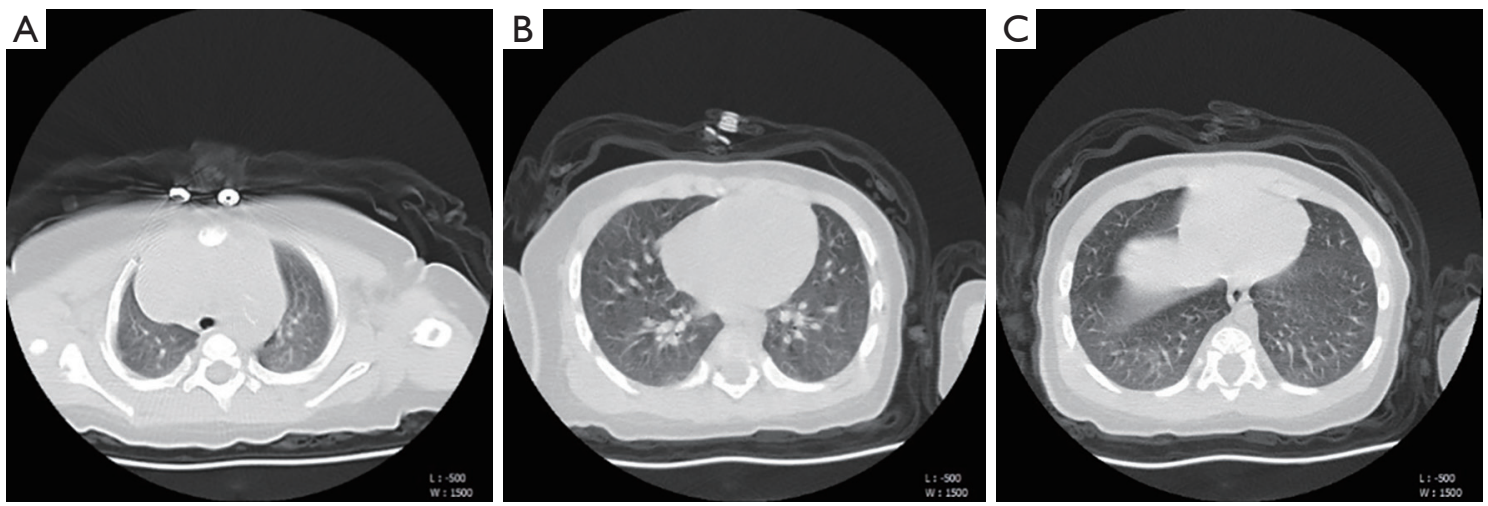

Figure 7 Third imaging findings of patient 1 (A,B,C): the 2-month follow-up CT showed the disappearance of pulmonary nodules. CT, computed tomography.

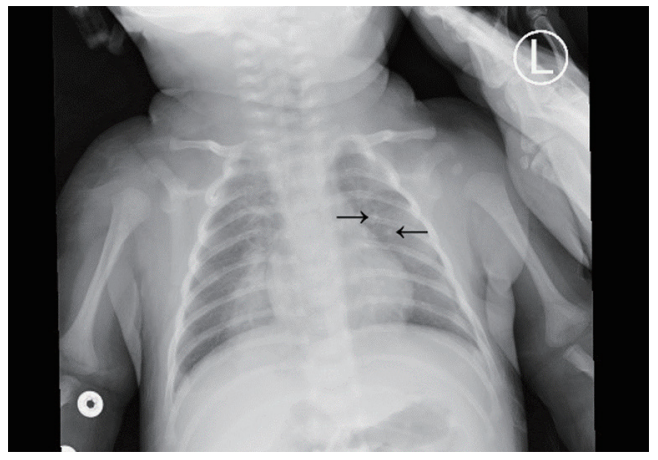

Figure 8 Imaging findings of patient 2: X-ray of the chest showed the upper lobe of the right lung was nodular such as the position of the black arrow in the picture.

were significant for mild thrombocytosis $\left(466 \times 10^{9} / \mathrm{L}\right)$, and the CRP was elevated $(45.92 \mathrm{mg} / \mathrm{L})$.

Due to the ineffective anti-infective treatment and the progressively elevated PLTs, we began to consider the possibility of incomplete Kawasaki disease. Echocardiography revealed a fusiform right coronary artery (1.8 $\mathrm{mm}$ in diameter) (see Figure 9) and a left fusiform coronary artery (2.5 $\mathrm{mm}$ in diameter) (see Figure 10). IVIG $(2 \mathrm{~g} / \mathrm{kg})$ was administered along with aspirin $(30 \mathrm{mg} / \mathrm{kg} / \mathrm{d})$. After treatment, the patient's temperature quickly returned to normal. He did not present with any periungual desquamation in the subacute phase. As the lung symptoms were not obvious at the time, we did not perform a reexamination of the chest $\mathrm{X}$-ray before he was discharged. A chest radiograph at a local hospital indicated that the lung nodules disappeared 1 month after being discharged. During the 3-month follow-up period, his coronary arteries also returned to normal (see Figures 11,12).

All procedures performed in studies involving human participants were in accordance with the ethical standards of the institutional and/or national research committee(s) and with the Helsinki Declaration (as revised in 2013). Written informed consent was obtained from both the patients' 


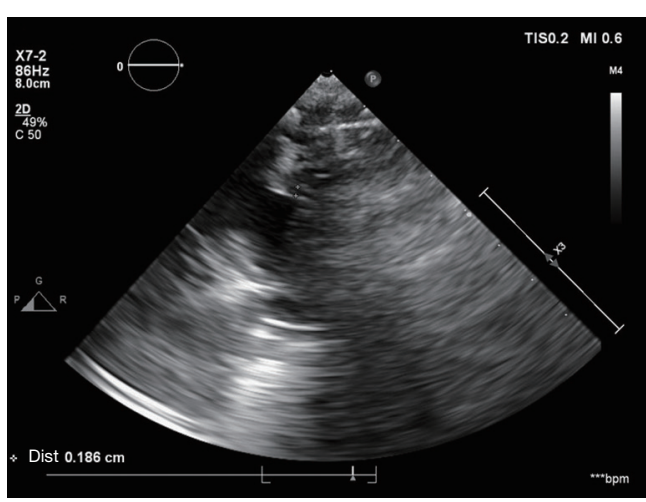

Figure 9 Right coronary artery picture of patient 2 .

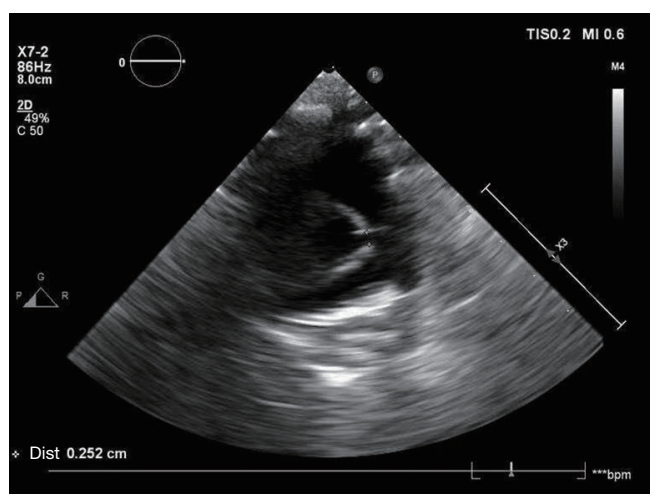

Figure 10 Left coronary artery picture of patient 2 .

parents.

\section{Discussion}

Pulmonary findings are not included in the classic diagnostic criteria for Kawasaki disease; however, chest radiograph abnormalities, including pulmonary nodules, have been observed in approximately $15 \%$ of patients, who may or may not have associated respiratory symptoms (11). In addition, pneumonia has been documented in $86 \%$ of autopsied acute stage Kawasaki disease cases (12). Pulmonary nodules are described as a sub-symptom in the American Heart Association scientific statement on the Kawasaki disease (4). Only 9 children have been reported to have pulmonary nodules associated with Kawasaki disease. We found that only 2 of 11 patients, including the 2 patients in this article, with Kawasaki disease complicated with pulmonary nodules, have had respiratory symptoms. The clinical features of the 11 cases are summarized in Table 1. Under the diagnostic guidelines for Kawasaki disease (6th revised edition), non-

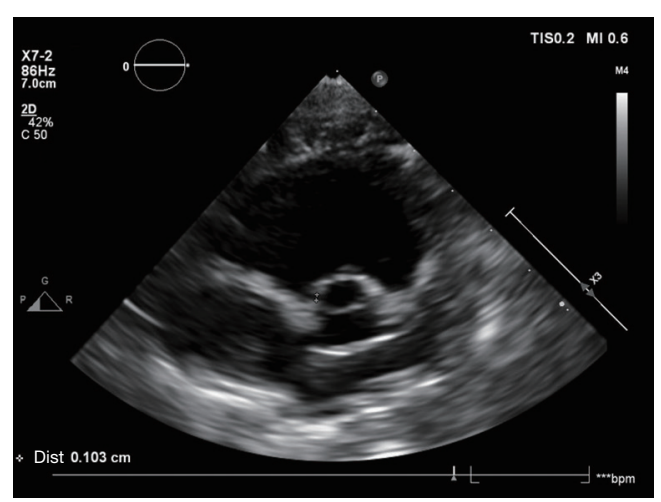

Figure 11 Reviewed right coronary artery picture of patient 2 .

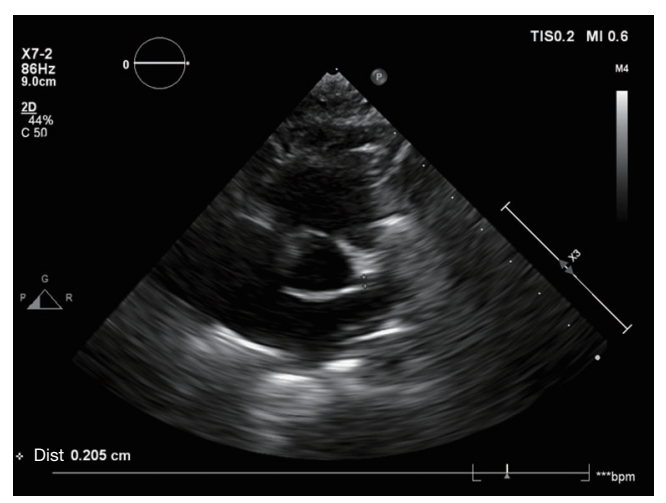

Figure 12 Reviewed left coronary artery picture of patient 2.

specific findings, such as respiratory symptoms (e.g., cough, rhinorrhea, and retropharyngeal edema), other irritability, abdominal pain, vomiting, diarrhea, and infiltrates on chest radiographs) maybe observed in Kawasaki disease and should not exclude a diagnosis (3).

A histological study of the nodules showed inflammatory cell infiltration surrounding several small and mediumsized arteries, as observed in coronary artery aneurysms in patients with Kawasaki disease (10). The pulmonary nodules of Kawasaki disease patients were inflammatory in nature, similar to the family of pseudo inflammatory tumors (IPTs). IPTs of the lung result from a benign reactive inflammatory process in which lymphocytes, plasma cells, and histiocytes infiltrate tissue, admixed with spindle-cell proliferation (13). Inflammatory pseudotumor formation is triggered by various stimuli, including infection, autoimmune illness, and trauma (14). In the previously reported cases, the lung nodules disappeared between 12 days and 1 year (5-10). The rapid involution of pulmonary nodules via standard Kawasaki disease treatment may reflect the inflammatory 
Table 1 The clinical features of the 11 cases

\begin{tabular}{|c|c|c|c|c|c|c|c|c|c|c|c|c|c|c|}
\hline \multirow[b]{2}{*}{ Case } & \multirow[b]{2}{*}{ Age } & \multirow[b]{2}{*}{ Sex } & \multicolumn{11}{|c|}{ Symptom } & \multirow[b]{2}{*}{ Ref. } \\
\hline & & & Fever & $\begin{array}{c}\text { Bilateral } \\
\text { bulbar } \\
\text { conjunctival } \\
\text { injection }\end{array}$ & $\begin{array}{l}\text { Changes } \\
\text { of lips } \\
\text { and oral } \\
\text { cavity }\end{array}$ & Rash & $\begin{array}{l}\text { Changes of } \\
\text { peripheral } \\
\text { extremities }\end{array}$ & $\begin{array}{l}\text { Non-supparative } \\
\text { cervical } \\
\text { lymphadenopathy }\end{array}$ & Cough & Dyspnea & $\begin{array}{l}\text { Chest } \\
\text { pain }\end{array}$ & Irritability & Diarrhea & \\
\hline 1 & $3 \mathrm{~m}$ & Male & $Y$ & $Y$ & $Y$ & $\mathrm{Y}$ & $\mathrm{Y}$ & $\mathrm{N}$ & $\mathrm{N}$ & $\mathrm{N}$ & $\mathrm{N}$ & $\mathrm{N}$ & $\mathrm{N}$ & (9) \\
\hline 2 & $4 \mathrm{~m}$ & Male & $\mathrm{Y}$ & $\mathrm{Y}$ & $\mathrm{N}$ & $\mathrm{N}$ & $\mathrm{N}$ & $\mathrm{N}$ & $\mathrm{N}$ & $\mathrm{N}$ & $\mathrm{N}$ & $\mathrm{N}$ & $\mathrm{Y}$ & (5) \\
\hline 3 & $4 \mathrm{~m}$ & Male & Y & $\mathrm{Y}$ & Y & $\mathrm{Y}$ & $Y$ & $\mathrm{~N}$ & $\mathrm{~N}$ & $\mathrm{~N}$ & $\mathrm{~N}$ & $\mathrm{Y}$ & $\mathrm{N}$ & (10) \\
\hline 4 & $6 \mathrm{~m}$ & Male & $Y$ & $Y$ & $\mathrm{~N}$ & $N$ & $\mathrm{~N}$ & $Y$ & $\mathrm{~N}$ & $\mathrm{~N}$ & $\mathrm{~N}$ & $Y$ & $\mathrm{~N}$ & (10) \\
\hline 5 & $5 \mathrm{~m}$ & Male & $\mathrm{Y}$ & $\mathrm{N}$ & $\mathrm{N}$ & $\mathrm{Y}$ & $\mathrm{N}$ & $\mathrm{N}$ & $\mathrm{N}$ & $\mathrm{N}$ & $\mathrm{N}$ & $\mathrm{N}$ & $Y$ & (10) \\
\hline 6 & $4 \mathrm{~m}$ & Female & $Y$ & $N$ & $Y$ & $Y$ & $Y$ & $N$ & $\mathrm{~N}$ & $\mathrm{~N}$ & $\mathrm{~N}$ & $\mathrm{~N}$ & $\mathrm{~N}$ & (7) \\
\hline 7 & $5 \mathrm{~m}$ & Female & $Y$ & $\mathrm{~N}$ & $Y$ & $Y$ & $Y$ & $N$ & $\mathrm{~N}$ & $\mathrm{~N}$ & $\mathrm{~N}$ & $N$ & $\mathrm{~N}$ & (7) \\
\hline 8 & $9 y$ & Female & $\mathrm{Y}$ & $\mathrm{Y}$ & $\mathrm{Y}$ & $\mathrm{Y}$ & $\mathrm{N}$ & Y & Y & $\mathrm{N}$ & Y & $\mathrm{N}$ & $\mathrm{N}$ & (6) \\
\hline 9 & $5 \mathrm{~m}$ & Male & $Y$ & U & N/A & N/A & N/A & N/A & $\mathrm{N} / \mathrm{A}$ & N/A & $\mathrm{N} / \mathrm{A}$ & N/A & $N / A$ & (8) \\
\hline 10 & $83 d$ & Male & $\mathrm{Y}$ & $\mathrm{Y}$ & $\mathrm{N}$ & $\mathrm{N}$ & $\mathrm{N}$ & $\mathrm{N}$ & Y & $\mathrm{N}$ & $\mathrm{N}$ & $\mathrm{Y}$ & $\mathrm{Y}$ & - \\
\hline 11 & $38 d$ & Male & $\mathrm{Y}$ & $\mathrm{N}$ & $\mathrm{N}$ & $\mathrm{N}$ & $\mathrm{N}$ & $\mathrm{N}$ & $\mathrm{N}$ & $\mathrm{N}$ & $\mathrm{N}$ & $\mathrm{Y}$ & $\mathrm{N}$ & - \\
\hline
\end{tabular}

Case 10-11: our cases. N/A, not available.

nature of the lesions.

Our cases illustrate that pulmonary nodules can be a feature of acute Kawasaki disease. Based on our findings and previous chest radiograph data, we speculate that pulmonary nodules may be present in acute Kawasaki disease complicated with coronary artery dilation (4-14). Thus, pulmonary nodules complicated with acute Kawasaki disease may enable the cautious observation of such lesions with serial CT scans for spontaneous resolution. Once a patient is diagnosed with Kawasaki disease and begins to show clinical improvement, follow-up CT scans will not be necessary. A biopsy should not be suggested unless the lesions do not show improvement after the acute Kawasaki disease has been treated.

\section{Conclusions}

In the 2 cases we reported, 1 of the patients presented with mild, transient bilateral conjunctival redness, and the other patient presented with a fever; thus, neither patient displayed all the typical symptoms of Kawasaki disease. Of the 9 cases previously reported, 7 (78\%) presented with coronary artery involvement. The mean age of the children was 5 months (ranging from 3 months to 9 years), and 8 $(89 \%)$ were infants [2-7]. We found that in these cases, not every patient had a typical manifestation of Kawasaki disease and that patients may only show 1 or 2 of the typical symptoms. However, atypical symptoms, such as a cough, irritability, and diarrhea, are more common. A high index of suspicion for the diagnosis of Kawasaki disease is particularly important in certain clinical situations. Prolonged fever or even no fever, irritability, and diarrhea may be important clinical manifestations of Kawasaki disease in infants.

Infants $\leq 6$ months of age are the most likely patients to present without clinical symptoms for Kawasaki disease. Such infants are at particularly high risk of developing coronary artery abnormalities. In the treatment of the first patient, we were initially viewed that the patient's irritability and loose stools complicated with thrombocytosis were manifestations of allergies. Similarly, in the treatment of the second patient, irritability and a culture-negative of cerebrospinal fluid suggestive of aseptic meningitis (treated meningitis) led to a diagnosis of Kawasaki disease being overlooked. Thus, in clinical work, if a child has a long fever that is unresponsive to anti-infective treatment or even no fever but unexplainable irritability and lung nodules, Kawasaki disease should be highly suspected.

In addition, it is important to note that pulmonary nodules are another clinical manifestation of Kawasaki 
disease. With the improvement of clinical manifestations after the regular treatment of Kawasaki disease, it is unnecessary to reexamine patients by undertaking a chest imaging examination, as these cases have shown that pulmonary nodules disappear, and there are no sequelae. A biopsy should not be suggested unless the lesions do not show improvement after the acute Kawasaki disease has been treated. However, future clinical studies need to explore further whether this kind of patient requires antibiotic treatment.

The parents of the patients expressed gratitude to us, and the treatments the patients received were timely and effective.

\section{Acknowledgments}

This paper has been edited by English Language Editors: L. Huleatt and J. Chapnick.

Funding: We acknowledge the support by Qingdao Municipal Hospital Clinical diagnosis and treatment Technology Innovation Fund Project (CXJJ-009).

\section{Footnote}

Reporting Checklist: The authors have completed the CARE reporting checklist. Available at https://dx.doi. org/10.21037/tp-21-66

Peer Review File: Available at https://dx.doi.org/10.21037/ tp-21-66

Conflicts of Interest: Both authors have completed the ICMJE uniform disclosure form (available at https://dx.doi. org/10.21037/tp-21-66). The authors have no conflicts of interest to declare.

Ethical Statement: The authors are accountable for all aspects of the work, including ensuring that any questions related to the accuracy or integrity of any part of the work have been appropriately investigated and resolved. All procedures performed in studies involving human participants were in accordance with the ethical standards of the institutional and/or national research committee(s) and with the Helsinki Declaration (as revised in 2013). Written informed consent was obtained from both the patients' parents.

Open Access Statement: This is an Open Access article distributed in accordance with the Creative Commons
Attribution-NonCommercial-NoDerivs 4.0 International License (CC BY-NC-ND 4.0), which permits the noncommercial replication and distribution of the article with the strict proviso that no changes or edits are made and the original work is properly cited (including links to both the formal publication through the relevant DOI and the license). See: https://creativecommons.org/licenses/by-nc-nd/4.0/.

\section{References}

1. Orenstein JM, Shulman ST, Fox LM, et al. Three linked vasculopathic processes characterize Kawasaki disease: a light and transmission electron microscopic study. PLoS One 2012;7:e38998.

2. Hoshino S, Tsuda E, Yamada O. Characteristics and fate of systemic artery aneurysm after Kawasaki disease. J Pediatr 2015;167:108-12.e1-2.

3. Kobayashi T, Ayusawa M, Suzuki H, et al. Revision of diagnostic guidelines for Kawasaki disease (6th revised edition). Pediatr Int 2020;62:1135-8.

4. McCrindle BW, Rowley AH, Newburger JW, et al. Diagnosis, treatment, and long-term management of Kawasaki disease: a scientific statement for health professionals from the American Heart Association. Circulation 2017;135:e927-99. Erratum in: Circulation 2019;140:e181-4.

5. Itani MH, Zakhour RG, Haddad MC, et al. Prolonged fever with pulmonary nodules in a 4-month-old baby. Pediatr Infect Dis J 2010;29:784, 788.

6. Higuchi Y, Ochi M, Shimizu J, et al. A 9-year-old girl with Kawasaki disease and pulmonary nodules. Clin Rheumatol 2020;39:3139-40.

7. Akagi K, Abe J, Tanaka K, et al. Kawasaki disease with pulmonary nodules and coronary artery involvement: a report of two cases and a review of the literature. Int J Rheum Dis 2017;20:1862-4.

8. Monedero Picazo MD, Gómez Fernández-Montes J, Molina Fábrega R, et al. Radiologic findings in the lungs of patients with Kawasaki disease. Radiologia 2006;48:14-8.

9. He T, Ling J, Chen J, et al. Intravenous immunoglobulinresistant Kawasaki disease with multiple pulmonary nodules: a case report and literature review. J Clin Pediatr 2020;38:490-2.

10. Freeman AF, Crawford SE, Finn LS, et al. Inflammatory pulmonary nodules in Kawasaki disease. Pediatr Pulmonol 2003;36:102-6.

11. Gibbons RJ, Smith S, Antman E, et al. American College of Cardiology/American Heart Association clinical practice 
guidelines: Part I: where do they come from? Circulation 2003;107:2979-86.

12. Gibbons RJ, Smith SC Jr, Antman E, et al. American College of Cardiology/American Heart Association clinical practice guidelines: Part II: evolutionary changes in a continuous quality improvement project. Circulation 2003;107:3101-7.

Cite this article as: Song D, Liu X. Kawasaki disease with pulmonary nodules: two case reports and literature review. Transl Pediatr 2021;10(7):1952-1959. doi: 10.21037/tp-21-66
13. Matsubara O, Tan-Liu NS, Kenney RM, et al. Inflammatory pseudotumors of the lung: progression from organizing pneumonia to fibrous histiocytoma or to plasma cell granuloma in 32 cases. Hum Pathol 1988;19:807-14.

14. Freud E, Bilik R, Yaniv I, et al. Inflammatory pseudotumor in childhood. A diagnostic and therapeutic dilemma. Arch Surg 1991;126:653-5. 